\title{
Autosomal dominant spastic paraplegia type 38
}

INSERM

\section{Source}

INSERM. (1999). Orphanet: an online rare disease and orphan drug data base. Autosomal dominant spastic paraplegia type 38. ORPHA:171617

A complex hereditary spastic paraplegia characterized by mild to severe lower limbs spasticity, hyperreflexia, extensor plantar responses, pes cavus and significant wasting and weakness of the small hand muscles. Impaired vibration sensation, temporal lobe epilepsy and cognitive dysfunction were also reported. 